\title{
Fiberconcrete with Non-Homogeneous Fibers Distribution
}

\author{
Vitalijs Lusis $^{1}$, Andrejs Krasnikovs ${ }^{2}$ \\ 1 - Riga Technical University, Concrete mechanics laboratory \\ 2 - Riga Technical University, Institute of Mechanics and Concrete mechanics laboratory \\ Address: 1 Kalku Street, Riga, LV-1658, Latvia
}

\begin{abstract}
In this research fiber reinforced concrete prisms with layers of non-homogeneous distribution of fibers inside them were elaborated. Fiber reinforced concrete is important material for load bearing structural elements. Traditionally fibers are homogeneously dispersed in a concrete. At the same time in many situations fiber reinforced concrete with homogeneously dispersed fibers is not optimal (majority of added fibers are not participating in load bearing process). It is possible to create constructions with non-homogeneous distribution of fibers in them in different ways. Present research is devoted to one of them. In the present research three different types of layered prisms with the same amount of fibers in them were experimentally produced (of this research prisms of nonhomogeneous fiber reinforced concrete with dimensions $100 \times 100 \times 400 \mathrm{~mm}$ were designed. and prisms with homogeneously dispersed fibers were produced for reference as well). Prisms were tested under four point bending conditions till crack opening in each prism reached $6 \mathrm{~mm}$. During the testing vertical deflection at the center of a prism and crack opening were fixed by the linear displacements transducers in real time.
\end{abstract}

Keywords - fiberconcrete, non-homogeneous fiber reinforced concrete, layered fibers' distribution, steel fibers.

\section{INTRODUCTION}

Fiber reinforced concrete is important material for load bearing structural elements. Conventional steel fibre reinforced concrete (SFRC) is fabricated by mixing steel fibres with a concrete mix. The volume fraction of fibres is limited to less than two percent. Although SFRC is a promising material, its flexural strength is yet to be exploited. Since ultimate stress required to fail fibre reinforced concrete (FRC) in flexure and tension is governed by fibre volume fraction, aspect ratio, fibre-matrix / bond strength and fibre distribution, increase in failure stresses can be achieved by increasing these parameters. In the present publication be investigated of fibers distribution and their spatial orientations in structural element volume $[2 ; 3 ; 4]$.

In this research fiber reinforced concrete prisms with layers of non-homogeneous distribution of fibers inside them were elaborated. Present research is devoted to one of them.

\section{MATERIALS AND METHODS}

In the framework of this research prisms of nonhomogeneous fiber reinforced concrete with dimensions $100 \times 100 \times 400 \mathrm{~mm}$ were designed. The technology of specimen preparation is described in the Latvian invention patent [5]. Three identical prisms of each type of non-homogeneous fiber reinforced concrete were prepared. Prisms were tested under four point bending conditions using Controls Automax 5 loading machine (Figure 1).

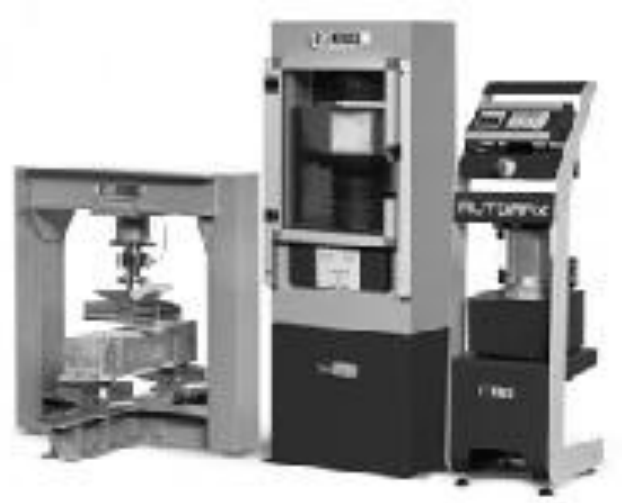

Fig.1. Concrete compression machine Controls Automax 5

All specimens with fibers are HPFRC with steelhooked fibers Dramix RC-80/30-BP with a length of $30 \mathrm{~mm}$ and a diameter of $0.38 \mathrm{~mm}$, for a fiber aspect ratio of 80 , and tensile strength $1020 \mathrm{MPa}$. These fibers are commercially available and manufactured by N.V. Bekaert S.A., Belgium (Figure 2).

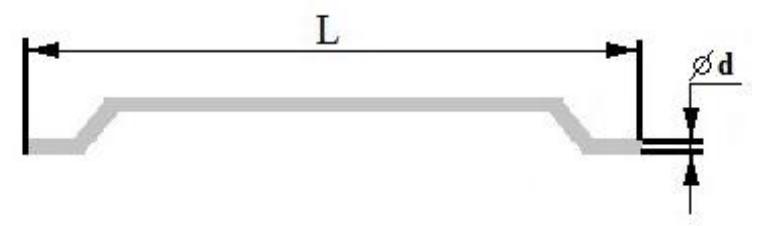

Fig.2. Steel fibers with curved ends $\mathrm{E}$ - anchor zone, mm; L length, $30 \mathrm{~mm}$; $\mathrm{d}$ - diameter of $0.38 \mathrm{~mm}$ 


\section{Mechanical properties of fibre concrete}

Verification of mechanical properties was performed in Experimental Concrete Mechanical laboratory (CML) according to standard 4-point bending test method. Test samples were tested after 28 days. Resistance strain gauges were placed on test samples. Load was applied in $0,25 \mathrm{kN}$ steps for period of $60 \mathrm{~s}$.

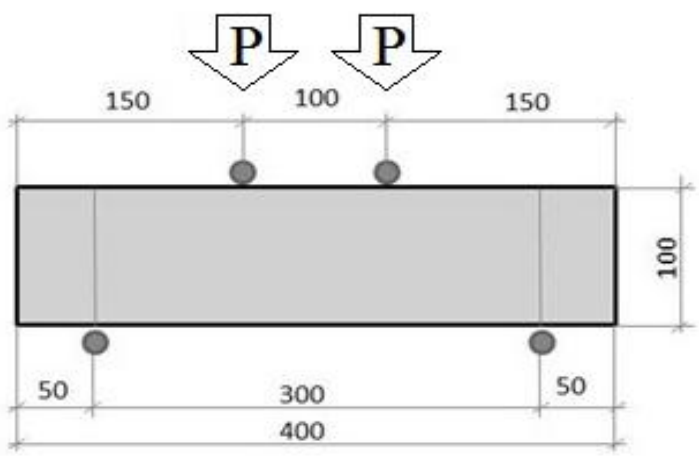

Fig.3. Tested under four point bending conditions

\section{Specimens' preparation}

Groups of specimens are presented in the Table 1. Group 1 consists of fiber reinforced concrete with fibers homogeneously dispersed in the sample volume.

TABLE 1.

\begin{tabular}{|c|c|}
\hline $\begin{array}{l}\text { Group } \\
\text { Nr. }\end{array}$ & $\begin{array}{l}\text { Distribution and concentration of fibers } \\
\text { in specimens }\end{array}$ \\
\hline $\begin{array}{l}\text { Group } \\
\text { Nr.1. }\end{array}$ & $\begin{array}{l}\text { Fibers mixed in concrete mixer and homogeneously } \\
\text { dispersed in the specimen (classical method) }\end{array}$ \\
\hline $\begin{array}{l}\text { Group } \\
\text { Nr.2. }\end{array}$ & $\begin{array}{l}\text { 1. } 25 \mathrm{~mm} \text { of concrete }-1 / 2 \text { of the total amount of } \\
\text { fibers }\left(60 \mathrm{~kg} / \mathrm{m}^{3}\right) \text { were pressed into concrete; } \\
\text { 2. } 25 \mathrm{~mm} \text { of concrete }-1 / 2 \text { of the total amount of } \\
\text { fibers }\left(60 \mathrm{~kg} / \mathrm{m}^{3}\right) \text { were pressed into concrete; } \\
\text { 3. } 50 \mathrm{~mm} \text { of concrete without fibers }\end{array}$ \\
\hline $\begin{array}{l}\text { Group } \\
\text { Nr.3. }\end{array}$ & $\begin{array}{l}\text { 1. } 25 \mathrm{~mm} \text { of concrete }-1 / 3 \text { of the total amount of } \\
\text { fibers }\left(60 \mathrm{~kg} / \mathrm{m}^{3}\right) \text { were pressed into concrete; } \\
\text { 2. } 25 \mathrm{~mm} \text { of concrete }-1 / 3 \text { of the total amount of } \\
\text { fibers }\left(60 \mathrm{~kg} / \mathrm{m}^{3}\right) \text { were pressed into concrete; } \\
\text { 3. } 25 \mathrm{~mm} \mathrm{of} \mathrm{concrete}-1 / 3 \text { of the total amount of } \\
\text { fibers }\left(60 \mathrm{~kg} / \mathrm{m}^{3}\right) \text { were pressed into concrete; } \\
\text { 4. } 25 \mathrm{~mm} \text { of concrete without fibers }\end{array}$ \\
\hline $\begin{array}{l}\text { Group } \\
\text { Nr.4. }\end{array}$ & $\begin{array}{l}\text { 1. } 55 \mathrm{~mm} \text { of concrete }- \text { fibers }\left(60 \mathrm{~kg} / \mathrm{m}^{3}\right) \text { were } \\
\text { pressed into concrete; } \\
2.45 \mathrm{~mm} \text { of concrete without fibers }\end{array}$ \\
\hline $\begin{array}{l}\text { Group } \\
\text { Nr.5. }\end{array}$ & $\begin{array}{l}\text { 1. } 25 \mathrm{~mm} \text { of concrete }-2 / 3 \text { of the total amount of } \\
\text { fibers }\left(60 \mathrm{~kg} / \mathrm{m}^{3}\right) \text { were pressed into concrete; } \\
\text { 2. } 75 \mathrm{~mm} \text { of concrete }-1 / 3 \text { of the total amount of } \\
\text { fibers }\left(60 \mathrm{~kg} / \mathrm{m}^{3}\right) \text { were pressed into concrete }\end{array}$ \\
\hline
\end{tabular}

These prisms were used as reference. As it is seen in Table 1, while the total amount of fibers is identical for all four groups of specimens, the difference is in their distribution. For specimens of Groups 2, 3 and 4 fibers are distributed in different layers with various concentration and distribution. These specimens can be defined as layered prisms with oriented distribution of fibers.

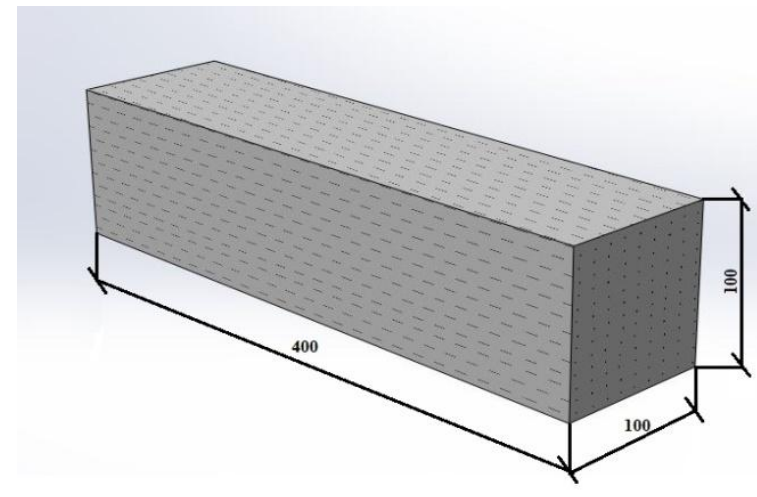

Fig. 4a. Group 1 distribution of fibers in specimens

Fibers were added to the mix during the concrete mixing process and moulds were filled by such fiberconcrete for specimens representing Group 1 (Figure 4a).

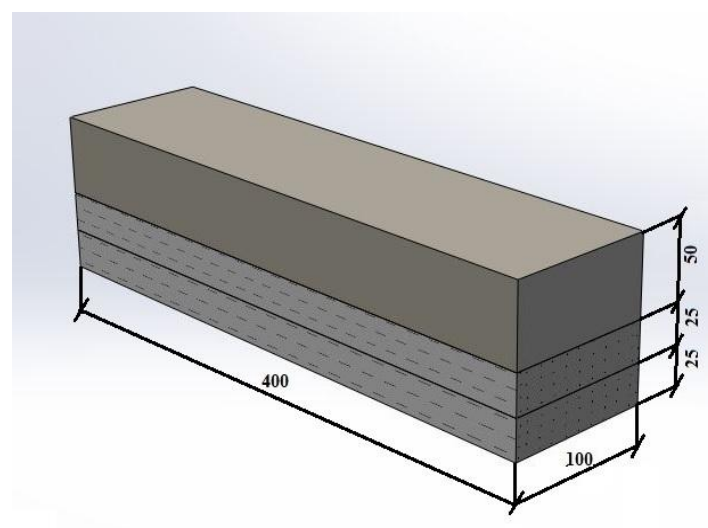

Fig. 4b. Group 2 distribution of fibers in specimens

Then fibers were uniformly scattered on the concrete surface in the mould and were pressed into concrete (Figure $4 \mathrm{~b}, 4 \mathrm{c}, 4 \mathrm{~d}$ and $4 \mathrm{e}$ ). For the specimen from Group 2 mould was filled with $25 \mathrm{~mm}$ layer of concrete mix, then fibers $(1 / 2$ of the total amount of fibers $60 \mathrm{~kg} / \mathrm{m}^{3}$ ) were uniformly scattered on the concrete surface in the mould and were pressed into concrete (2 layer) and layer $50 \mathrm{~mm}$ of concrete mix, non fibers (Figure 4b).

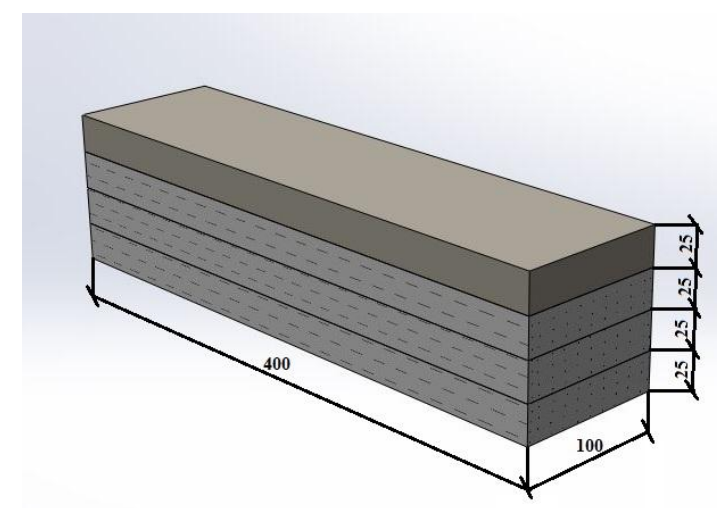

Fig. 4c. Group 3 distribution of fibers in specimens

For the specimens from Groups 2, 3, 4 and 5 moulds were gradually filled with the concrete mix according to the description of each group. 
Fibers were pressed by a steel grid into the concrete in the full length of the prism according to the Latvian invention patent LV14257 technology [5].

For the specimen from Group 3 mould was filled with $25 \mathrm{~mm}$ layer of concrete mix, then fibers $(1 / 3$ of the total amount of fibers $60 \mathrm{~kg} / \mathrm{m}^{3}$ ) were uniformly scattered on the concrete surface in the mould and were pressed into concrete (3 layer) and layer $25 \mathrm{~mm}$ of concrete mix, non fibers (Figure 4c).

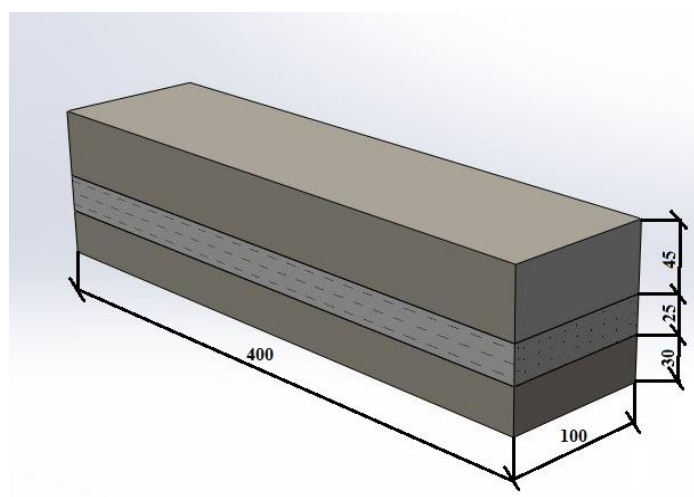

Fig. 4d. Group 4 distribution of fibers in specimens

For the specimen from Group 4 mould was filled with concrete mix up to $55 \mathrm{~mm}$ and the rest of all fibers $\left(60 \mathrm{~kg} / \mathrm{m}^{3}\right)$ were uniformly scattered on the concrete surface in the mould and were pressed into concrete. Fibers were pressed by a steel grid. Finally, mould was filled with concrete mix up to $100 \mathrm{~mm}$ (Figure 4d).

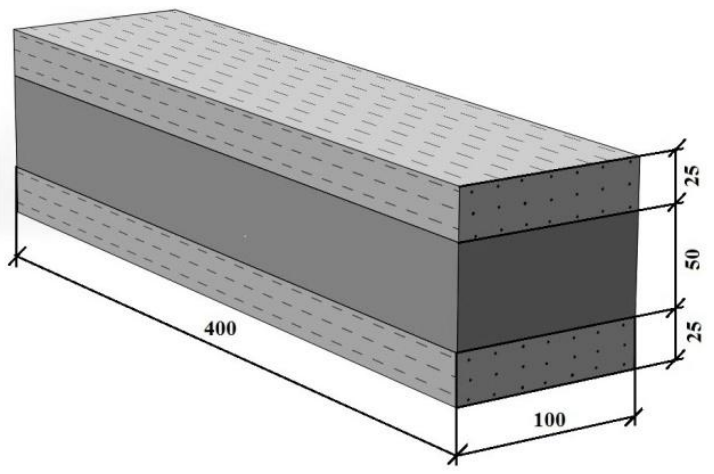

Fig. 4e. Group 5 distribution of fibers in specimens

For the specimen from Group 5 mould was filled with $25 \mathrm{~mm}$ layer of concrete mix, then fibers $(2 / 3$ of the total amount of fibers $60 \mathrm{~kg} / \mathrm{m}^{3}$ ) were uniformly scattered on the concrete surface in the mould and were pressed into concrete, further layer $75 \mathrm{~mm}$ of concrete mix, non fibers and fibers (1/3 of the total amount of fibers $60 \mathrm{~kg} / \mathrm{m}^{3}$ ) were uniformly scattered on the concrete surface in the mould and were pressed into concrete (Figure 4e).

Density of fiber reinforced concrete ranges from 2370 to $2430 \mathrm{~kg} / \mathrm{m}^{3}\left(2400 \mathrm{~kg} / \mathrm{m}^{3}\right.$ in average $)$ and according to the concrete compressive strength testing results it corresponds to the compressive strength class C70/85. All specimens, namely, fiber reinforced concrete prisms were tested under four point bending conditions using Controls Automax 5 testing machine (Figure 5).

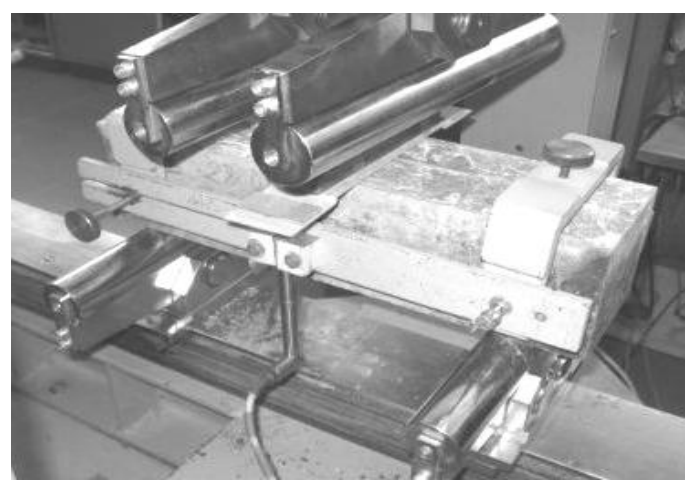

Fig. 5.Testing device with fiber reinforced concrete prism inside it

During the testing vertical deflection at the centre of a prism and crack opening were fixed by the linear displacements transducers in real time. Load bearing chart for the specimen is given in Figure 3. Sensors were connected throw the data acquisition unit to computer where the obtained data were recorded and were available after experiments.

\section{RESULTS AND DISCUSSION}

Specimens were tested under four point bending conditions till the macro crack opening was reached 6 $\mathrm{mm}$.

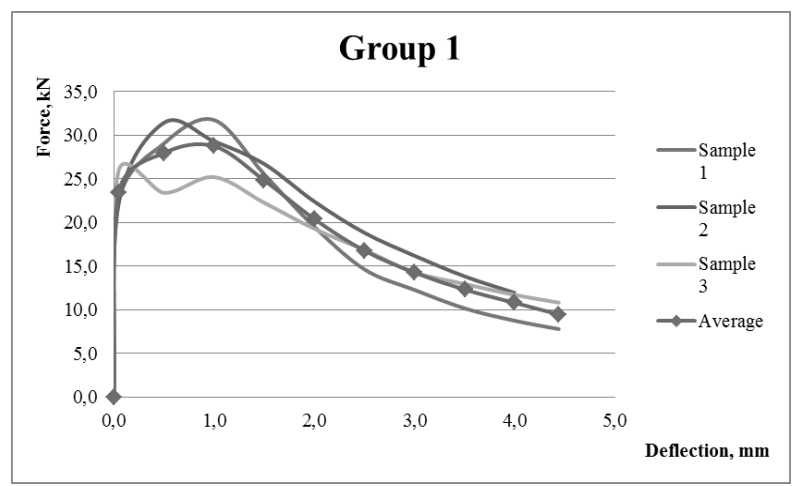

Figure 6a. Load - vertical deflection graphs for specimens in Group Nr.1.

Load bearing - vertical deflection at the centre of each prism graphs for the specimens of Group 1 are given in Figure 6a.

The diagram shows the experimental curve of each specimen as well as the average value curve. Three stages are seen in each curve; first of them is linear elastic deflection (corresponds to deflection under $0,01 \mathrm{~mm}$ ). In this stage fiber reinforced concrete prisms become deformed without visible crack openings. 


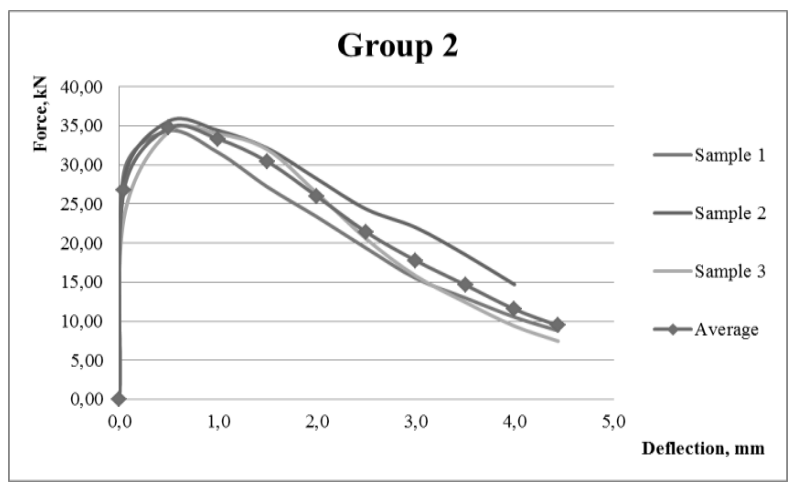

Figure 6b. Load - vertical deflection graphs for specimens in Group Nr.2

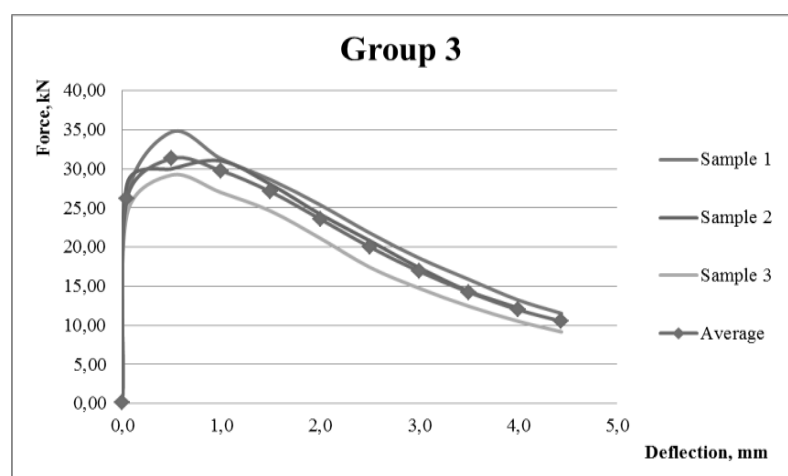

Figure 6c. Load - vertical deflection graphs for specimens in Group Nr.3

Fibers in the concrete do not bear significant load. The next stage begins with deviation of curves from the straight line and terminates reaching the maximum value on curve (with deflection of prisms $0,75 \mathrm{~mm}-$ $1 \mathrm{~mm})$.

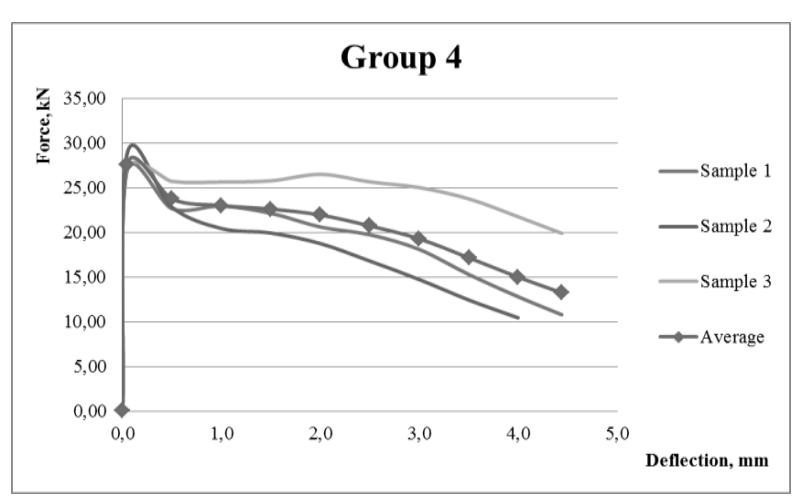

Figure 6d. Load - vertical deflection graphs for specimens in Group Nr.4

In this stage concrete micro cracks accumulate and grow forming macro crack network. The macro cracks are formed perpendicularly to the longitudinal axis of prism. Density of macro crack network depends on specimen's geometry, size of fibers and their amount. Fibers traversing macro cracks begin to bear load, while cracks are still invisible on the outer surface of specimen.

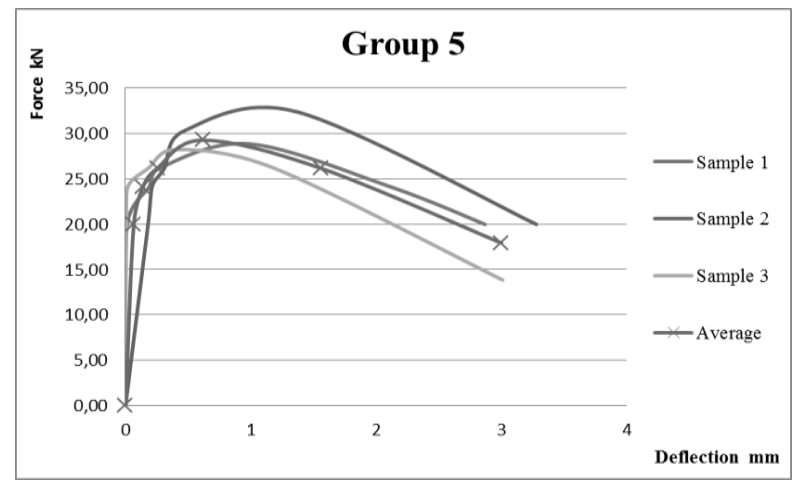

Figure 6e. Load - vertical deflection graphs for specimens in Group Nr.5

Crack with the lowest load carrying capacity (one with the lower amount of fibers traversing it or fibers located and oriented in a less optimal way) starts to open. It proceeds the following way: fibers bearing load detach from the concrete and start pulling out from one or both ends. Individual load carrying capacity of fiber depends on its distribution towards the crack plane and how far it is extracted.

Experimental observation of fiber pull-out micromechanics [1] showed that the maximum load carrying capacity of fiber depends on the distribution of fiber towards direction of extraction force and how much the fiber has been extracted. The third stage is characterised by the decline of total load carrying capacity of fiber. The capacity decreases proportionally to the size of crack opening. Load bearing - vertical deflection at the center of prism for the specimens of Groups 2, 34 and 5 are given in Figures 6b-6e.

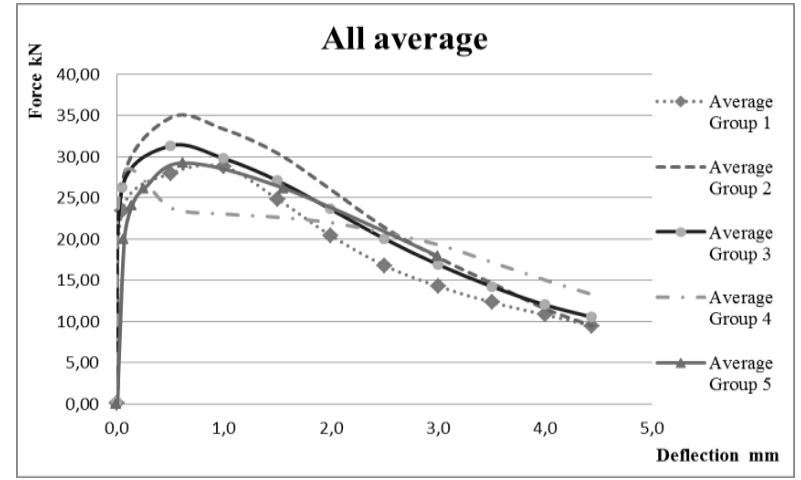

Figure 7. Load - vertical deflection graphs for specimens in comparison of average of all sample groups

Diagrams in Figures 6a-6e show the average experimental curves from three specimens. Experimental (average) curves for all five groups are given in Figure 7. As it can be observed, Group 2 reaches the highest load carrying capacity during crack opening stage due to the highest concentration of fibers compared to other groups in the lower part of the prism which bears the maximum tensile load (see Figure 8). 


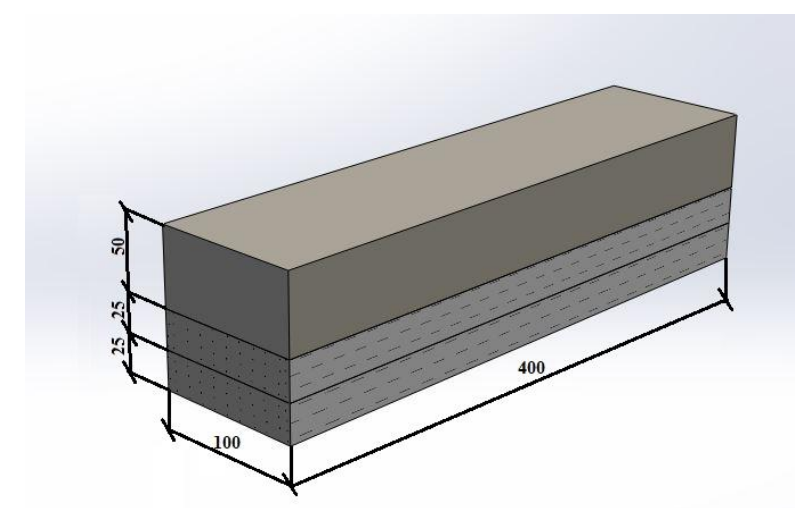

Figure 8.Group 2 distribution of fibers in specimens

As it can be observed, Group 1 (reference specimens) reaches lower average load carrying capacity in the third stage (macro cracks) compared to the specimens with non-homogeneous distribution of fibers. Certain similar tendencies can be observed among the diagrams of average results of specimens the maximal load carrying capacity is reached with deflection of prisms $0,75 \mathrm{~mm}-1 \mathrm{~mm}$, which correlates with the crack opening size.

\section{CONCLUSION}

The weight reduction of concrete floor structures has recently gained importance in regards to the increased demands on construction materials savings and on further savings related to transportation. The motivation is not only economical but also environmental influenced sustainable development which is becoming more important. In this research fiber reinforced concrete with the concentration of steel fibers $60 \mathrm{~kg} / \mathrm{m}^{3}$ were tested. Fibers were incorporated into concrete specimens in four different ways. Specimens were tested under four point bending conditions observing their load carrying capacity in the macro cracking stage. In specimens of Group 1 fibers were dispersed in all the specimen volume, in specimens of Groups 2, 3, 4 and 5 they were distributed in various layers with specified amount of fibers in each of them. According to the testing results, specimens of Group 2 reached the highest load carrying capacity during crack opening stage as they had the highest concentration of fibers in the part of prisms experiencing maximum tensile load they exhibit improved strength and ductility related properties compared other Group samples. Specimens of Group 1 showed lower average load carrying capacity during crack forming stage compared to the specimens with non-homogeneous distribution of fibers.

\section{ACKNOWLEDGMENTS}

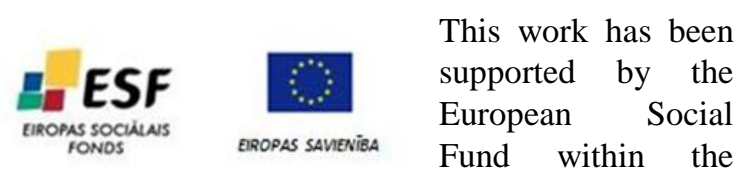

project «Support for the implementation of doctoral studies at Riga Technical University».

\section{REFERENCES}

[1] Krasnikovs A., Kononova O., Khabaz A., Machanovsky E. and Machanovsky A. (2012) Post-Cracking Behavior of High Strength (Nano Level Designed) Fiber Concrete Prediction and Validation. CD-Proceedings of 4th International Symposium on Nanotechnology in Construction, 20-22 May 2012, Crete, Greece, 6 p.

[2] Krasnikovs A., Kononova O. strength prediction for concrete reinforced by different length and shape short steel fibers// Sc. Proceedings of Riga Technical University. Transport and Engineering, 6, vol.31, p.89-93, 2009.

[3] Lusis V., Galushchaka A., Machanovskis A., Kononova O., Krasnikovs A., Strength of layered fiberconcrete. Civilengineering 13 Conference proceedings. 2013, p. 5.

[4] Li V. C. (2003) On Engineered Cementitious Composites a Revue of the Material an it's Applications. Journal of Advanced Concrete Technology, Vol.1, No3, p. 215-230.

[5] Lapsa V., Krasnikovs A., Strauts K., (2011.20.04) „Fiberconcrete Non-Homogeneous Structure Element Building Technology Process and Equipment", Latvian invention patent LV14257. 